\title{
pesquisa
}

RESENDE, G.M.; YURI, J.E.; MOTA, J.H.; RODRIGUES JÚNIOR, J.C.; SOUZA, R.J.; CARVALHO, J.G. Produção de alface americana em função de doses e épocas de aplicação de Supa Potássio ${ }^{\circledR}$. Horticultura Brasileira, Brasília, v.23, n.2, p.174-178, abr-jun 2005.

\section{Produção de alface americana em função de doses e épocas de aplicação de Supa Potássio ${ }^{\circledR}$}

\author{
Geraldo M. de Resende ${ }^{1}$; Jony E. Yuri²; José H. Mota ${ }^{3}$; Juarez C. Rodrigues Júnior ${ }^{4}$; Rovilson J. de \\ Souza ${ }^{5}$ Janice G. de Carvalho ${ }^{5}$ \\ ${ }^{1}$ Embrapa Semi-Árido, C. Postal 23, 56302-970 Petrolina-PE; ${ }^{2}$ Doutorando em Fitotecnia pela UFLA; ${ }^{3}$ Bolsista DCR, UFMS; ${ }^{4}$ Agromax, \\ Rua Tiradentes, 12, 37750-000 Machado-MG; ${ }^{5}$ UFLA, C. Postal 37, 37200-000 Lavras-MG; E-mail: gmilanez@cpatsa.embrapa.br
}

\section{RESUMO}

Avaliou-se a influência de doses de Supa Potássio ${ }^{\circledR}$ sobre o rendimento e qualidade da alface americana em três ensaios distintos, de novembro de 2002 a janeiro de 2003, no município de Três Pontas (MG). Utilizou-se o delineamento de blocos ao acaso em quatro repetições, com cinco doses de Supa Potássio ${ }^{\circledast}(0,0 ; 4,5 ; 9,0 ; 13,5$ e $18,0 \mathrm{~L} / \mathrm{ha}$ ) o qual possui $20 \%$ de $\mathrm{SiO}_{2}$ e $15 \%$ de $\mathrm{K}$, aplicadas em três épocas via foliar (14; 21 e 28 dias após o transplantio). A massa fresca total apresentou efeito quadrático na qual a dose $8,6 \mathrm{~L} / \mathrm{ha}$ de Supa Potássio ${ }^{\circledast}$ resultou em maior rendimento. Para épocas de aplicação, foram observadas diferenças significativas, tendo a aplicação aos 14 dias sobressaído com 706,0 g/planta. Constatou-se que a aplicação de 10,5 L/ha de Supa Potássio ${ }^{\circledR}$ possibilitou o maior retorno em termos de massa fresca comercial. Para aplicação aos 21 e 28 dias após o transplantio evidenciou-se efeitos quadráticos onde as doses de 4,3 e 9,8 1/ha de Supa Potássio ${ }^{\circledR}$ propiciaram a melhor conservação pós-colheita da alface. A circunferência da cabeça e o comprimento de caule não foram significativamente influenciados pelas doses de Supa Potássio ${ }^{\circledast}$.

Palavras-chave: Rendimento, nutrição, qualidade.

\begin{abstract}
Production of crisphead lettuce affected by rates and application time of Supa Potássio ${ }^{\circledR}$

Three trials were carried out in Três Pontas, Brazil, from November 2002 to January 2003, to evaluate the effects of Supa Potássio ${ }^{\circledR}$ doses on yield and quality of crisphead lettuce. Five doses of Supa Potássio ${ }^{\circledast}(0.0 ; 4.5 ; 9.0 ; 13.5$ and $18.0 \mathrm{~L} / \mathrm{ha})$, with $20 \% \mathrm{SiO} 2$ and $15 \% \mathrm{~K}$ and three foliar application times $(14 ; 21$ and 28 days after planting date) were tested using a randomized complete blocks design with four replications. Each application time was considered one trial. The total fresh mass presented quadratic effect and the dose $9.1 \mathrm{~L} /$ ha of Supa Potássio ${ }^{\circledR}$ resulted in the largest revenue. There were significant differences between time of foliar application for plant fresh weight and plants with 706,0 g were harvested when Supa Potassio ${ }^{\circledR}$ was applied 14 days after transplant. The application of $10.5 \mathrm{~L} / \mathrm{ha}$ of Supa Potássio ${ }^{\circledast}$ promoted the highest commercial fresh matter. Applications at 21 and 28 days after planting date showed a quadratic effect and the doses of 4.3 and $9.8 \mathrm{~L} / \mathrm{ha}$ of Supa Potássio ${ }^{\circledast}$ presented the best post-harvest storage of the crisphead lettuce. Supa Potássio ${ }^{\circledR}$ had no significant effect on head circumference and stem length.
\end{abstract}

Keywords: Yield, nutrition, quality.

(Recebido para publicação em 17 de dezembro de 2003 e aceito em 9 de fevereiro de 2005)

\begin{abstract}
A alface americana (Lactuca sativa L.), vem adquirindo importância crescente no país. O plantio deste tipo de alface visa atender as redes "fast food" e, atualmente, tem-se constatado aumento no consumo desta hortaliça também na forma de salada.

O silício é o segundo elemento mais abundante em peso na crosta terrestre, sendo o maior componente de minerais do grupo dos silicatos (RAIJ, 1991). Ocorre em altos teores em solos minerais, principalmente na forma de silicatos, e no quartzo ( $\mathrm{Si}_{2}$, mineral inerte das areias). É um elemento com propriedades condutoras e físicas de um semi-metal, desempenhando, no reino mineral, um papel cuja importância pode ser comparável ao carbono nos
\end{abstract}

reino vegetal e animal. Ocupa cerca de 23 a $35 \%$ em peso na maioria dos solos, valores de $40 \%$ podem ser encontrados em solos arenosos, e valores de apenas 9\% podem ocorrer em solos tropicais mais intemperizados (TISDALE et al., 1985).

As diferentes espécies de plantas variam grandemente em sua capacidade de acumular Si nos tecidos, podendo, em função dos percentuais de $\mathrm{SiO}_{2}$ na matéria seca, ser divididas em plantas acumuladoras, que incluem muitas gramíneas como o arroz, as quais contêm de $10 \%$ a $15 \%$ de $\mathrm{Si}_{2}$; intermediárias, com teores de $\mathrm{SiO}_{2}$ variando de $1 \%$ a 5\% (cereais, cana-de-açúcar, algumas dicotiledôneas) e não acumuladoras $\left(<0,5 \% \mathrm{SiO}_{2}\right)$, incluindo a maioria das dicotiledôneas, como as leguminosas e muitas espécies arbóreas (TAKAHASHI; MIYAKE, 1997; FAQUIN, 1997; MARSCHNER, 1995).

A sílica solúvel tem sido pouco estudada, principalmente pelo fato do silício não ser considerado elemento essencial às plantas. Entretanto inúmeros trabalhos têm demonstrado o efeito benéfico da sua utilização em diversas culturas. A sua função estrutural na parede celular pode elevar os conteúdos de hemicelulose e lignina, aumentando a rigidez da célula. Há relatos de que atua no aumento da produção de grãos em arroz (BARBOSA FILHO et al., 2001) na tolerância ao Mn e na redução da toxicidade por Fe em feijoeiro (HORST; MARSCHNER, 1978), no aproveitamento e deslocamento do $\mathrm{P}$ 
pelo $\mathrm{Si}$, que ao saturar os sítios de adsorção dos óxidos de Fe e Al da fração argila, impede ou dificulta a adsorção do $\mathrm{P}$, tornando-o mais disponível em solução (LEITE, 1997; CARVALHO et al., 2000). A ação benéfica do silício tem sido associada a diversos efeitos indiretos, como o aumento na eficiência da capacidade fotossintética, redução da transpiração, aumento da resistência mecânica das células, na resistência a insetos e doenças, na redução da acumulação tóxica de Mn, Fe e Al e outros metais pesados, e aumento na absorção do P (KORNDÖRFER; DATNOFF, 1995). Pode estimular o crescimento e a produção vegetal por meio de várias ações indiretas, deixando as folhas mais eretas, com diminuição do auto-sombreamento, redução no acamamento, maior rigidez estrutural dos tecidos, proteção contra estresses abióticos, como a redução da toxidez de $\mathrm{Fe}, \mathrm{Mn}, \mathrm{Al}$ e Na, diminuição na incidência de patógenos e aumento na proteção contra herbívoros, incluindo os insetos fitófagos (EPSTEIN, 1994; MARSCHNER, 1995).

O crescimento e a produtividade de muitas gramíneas como arroz, cana-deaçúcar, sorgo, milheto, aveia, trigo, milho, grama bermuda, etc., têm mostrado incrementos com o aumento da disponibilidade de Si para as plantas, notadamente aquelas consideradas acumuladoras do elemento em seus tecidos (KORNDÖRFER; DATNOFF, 1995; MARSCHNER, 1995). O silício mostrou, também, benefícios ao pepino, por aumentar a resistência à ocorrência de doenças fúngicas e favorecer a fotossíntese (ADATIA; BESFORD, 1986).

O potássio é normalmente o segundo nutriente mais exigido pelas culturas, depois do nitrogênio (FAQUIN, 1997). É considerado um ativador enzimático; regulador da turgidez do tecido; controlador da abertura e do fechamento de estômatos, possibilitando o controle da concentração de $\mathrm{CO}_{2}$ na câmara sub-estomática, a qual afeta diretamente a atividade fotossintética e a transpiração (HOPKINS, 1995). Segundo Mengel e Kirkby (1987), ainda atua no transporte de carboidratos. Diminui os danos causados por geadas, pela seca e por salinidade (DOUGLAS, 1985). A presença de potássio aumenta a resis- tência ao acamamento e a resistência às doenças, pois acelera o processo de lignificação das células esclerenquimáticas, aumentando a espessura da parede celular (MARSCHNER, 1995). Tem participação na qualidade dos produtos, aumentando a resistência ao transporte, manuseio e armazenamento, melhorando a cor, o tamanho, a acidez e o valor nutritivo dos alimentos (RISSE et al., 1989).

A falta de informações sobre o uso de silício na cultura da alface, justificou o presente trabalho, que objetivou avaliar diferentes doses e épocas de aplicação de Supa Potássio ${ }^{\circledR}$, sobre as características produtivas e qualidade póscolheita da alface americana em condições de campo, no verão.

\section{MATERIAL E MÉTODOS}

Foram conduzidos três ensaios, de novembro de 2002 a janeiro de 2003, no município de Três Pontas (MG), em propriedade comercial situada a uma altitude de $870 \mathrm{~m}$. O solo predominante da área experimental foi classificado como LATOSSOLO VERMELHO Distroférrico de textura argilosa. A análise do solo onde foi instalado o experimento apresentou as seguintes características: $\mathrm{K}=101 \mathrm{mg} \mathrm{dm}^{-3} ; \mathrm{P}=44,9 \mathrm{mg}$ $\mathrm{dm}^{-3} ; \mathrm{Ca}=4,0 \mathrm{cmol}_{\mathrm{c}} \mathrm{dm}^{-3} ; \mathrm{Mg}=0,8$ $\mathrm{cmol}_{\mathrm{c}} \mathrm{dm}^{-3} ; \mathrm{Al}=0,0 \mathrm{cmol}_{\mathrm{c}} \mathrm{dm}^{-3} ; \mathrm{H}+\mathrm{Al}$

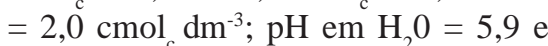
matéria orgânica $=2,0 \mathrm{dag} \mathrm{\textrm {kg } ^ { - 1 }}$.

Utilizou-se a cultivar Raider no delineamento de blocos ao acaso com cinco doses de Supa Potássio ${ }^{\circledR}(0,0 ; 4,5$; $9,0 ; 13,5$ e $18,0 \mathrm{~L} / \mathrm{ha})$, o qual possui $20 \%$ de $\mathrm{SiO}_{2}$ e $15 \%$ de $\mathrm{K}$ e quatro repetições, aplicadas em três épocas, via foliar (14; 21 e 28 dias após o transplantio), sendo cada época de aplicação considerada um ensaio. As aplicações foliares foram realizadas com pulverizador manual com $4 \mathrm{~L}$ de capacidade, em máxima pressão, gastando-se $300 \mathrm{~L}$ de calda por hectare.

As parcelas experimentais constituíram-se de quatro linhas de $2,1 \mathrm{~m}$ de comprimento, espaçadas de $0,30 \mathrm{~m}$, com $0,35 \mathrm{~m}$ entre plantas. As linhas centrais formaram a área útil, desprezando-se as duas plantas de cada extremidade. A adubação de plantio de acordo com a análise de solo constou de 1,7 t/ha da formula 04-14-08 e 1,0 t/ha de superfosfato simples incorporados em toda a extensão do canteiro. As adubações de cobertura foram realizadas por fertirrigações diárias, totalizando $40 \mathrm{~kg} /$ ha de $\mathrm{Ne} 85 \mathrm{~kg} / \mathrm{ha}$ de $\mathrm{K}$, utilizando como fontes a uréia e o cloreto de potássio, não havendo necessidade de calagem de acordo com as recomendações de Alvarez V. e Ribeiro (1999). O transplante das mudas com 30 dias de idade foi feito em 25/ $11 / 2002$, irrigando-se diariamente, sendo a cultura conduzida sob "mulching". Os demais tratos culturais foram os comuns à cultura.

As colheitas foram feitas em 08/01/ 2003, sendo avaliadas a massa fresca total e comercial (g/planta); circunferência e comprimento do caule da cabeça comercial $(\mathrm{cm})$ e conservação pós-colheita aos 10 e 20 dias em câmara frigorífica a $5 \pm 2^{\circ} \mathrm{C}$, avaliada por notas (nota $1=$ cabeças comerciais extremamente deterioradas; $2=$ cabeças comerciais deterioradas; $3=$ cabeças comerciais moderadamente deterioradas; 4=cabeças comerciais levemente deterioradas e $5=$ cabeças comerciais sem deterioração), sendo utilizados três avaliadores e obtida a média das notas. Os dados relativos aos três ensaios foram submetidos à análise de variância conjunta, sendo as médias de épocas de aplicação comparadas pelo teste de Tukey e as doses de Supa Potássio ${ }^{\circledR}$ por regressão polinomial ao nível de $5 \%$ de probabilidade.

\section{RESULTADOS E DISCUSSÃO}

Os efeitos foram significativos e independentes para as doses de Supa Potássio ${ }^{\circledR}$ e época de aplicação, assim como para a interação entre estes fatores, variando com as características avaliadas. A massa fresca total evidenciou efeitos significativos independentes para as doses de Supa Potássio ${ }^{\circledR}$ e épocas de aplicação. Para os dados relativos as doses ajustou-se um modelo quadrático, pelo qual se estimou a dose $8,6 \mathrm{~L} / \mathrm{ha}$ como a que proporcionou maior rendimento (Figura 1). Avaliando o efeito das épocas de aplicação sobre a massa fresca total, houve variação de 660,95 a 706,00 g/planta, tendo a aplicação aos 14 dias após o transplante se mostrado 
Tabela 1. Massa fresca total e comercial (g/planta), circunferência da cabeça comercial $(\mathrm{cm})$, comprimento do caule da cabeça comercial $(\mathrm{cm})$ e conservação pós-colheita aos 10 e 20 dias após a colheita (notas) da alface americana em função do uso de doses e épocas de aplicação de Supa Potássio ${ }^{\circledR}$ (média de quatro repetições). Três Pontas (MG), UFLA, 2002/2003.

\begin{tabular}{|c|c|c|c|c|c|}
\hline \multirow{2}{*}{ Características } & \multicolumn{5}{|c|}{ Épocas de aplicação (dias após transplantio) } \\
\hline & \multicolumn{2}{|l|}{14} & \multicolumn{2}{|l|}{21} & 28 \\
\hline Massa fresca total ${ }^{* *}$ & \multicolumn{2}{|l|}{$706,00 \mathrm{a}$} & $660,95 \mathrm{~b}$ & \multicolumn{2}{|r|}{$671,35 a b$} \\
\hline Massa fresca comercial Ns & \multicolumn{2}{|l|}{$401,70 \mathrm{a}$} & 387,70 a & \multicolumn{2}{|r|}{395,25 a } \\
\hline Circunferência da cabeça comercial $(\mathrm{cm})^{\mathrm{NS}}$ & \multicolumn{2}{|l|}{37,73 a } & $37,01 \mathrm{a}$ & \multicolumn{2}{|r|}{37,09 a } \\
\hline Comprimento do caule da cabeça comercial $(\mathrm{cm})^{\mathrm{NS}}$ & \multicolumn{2}{|c|}{$6,02 \mathrm{a}$} & 6,39 a & \multicolumn{2}{|r|}{$6,40 \mathrm{a}$} \\
\hline Conservação pós-colheita (10 dias) ${ }^{\mathrm{NS}}$ & \multicolumn{2}{|c|}{$4,47 \mathrm{a}$} & $4,57 \mathrm{a}$ & \multicolumn{2}{|r|}{$4,60 \mathrm{a}$} \\
\hline \multirow[t]{3}{*}{ Conservação pós-colheita* (20 dias) } & $2,87 b$ & & $2,95 \mathrm{ab}$ & & $3,18 \mathrm{a}$ \\
\hline & \multicolumn{5}{|c|}{ Doses de Supa Potássio ${ }^{\circledR}$ (L/ha) } \\
\hline & 0,0 & 4,5 & 9,0 & 13,5 & 18,0 \\
\hline Circunferência da cabeça comercial $(\mathrm{cm})^{\mathrm{NS}}$ & $37,12 \mathrm{a}$ & $37,65 \mathrm{a}$ & $37,43 a$ & $37,08 \mathrm{a}$ & $37,09 \mathrm{a}$ \\
\hline Comprimento do caule da cabeça comercial $(\mathrm{cm})^{\mathrm{NS}}$ & $6,37 \mathrm{a}$ & 6,40 a & $6,15 a$ & 6,16 a & 6,45 a \\
\hline Conservação pós-colheita (10 dias) ${ }^{\mathrm{NS}}$ & $4,59 \mathrm{a}$ & 4,67 a & $4,57 \mathrm{a}$ & $4,56 \mathrm{a}$ & $4,57 \mathrm{a}$ \\
\hline
\end{tabular}

Médias seguidas pela mesma letra nas linhas, não diferem entre si, pelo teste de Tukey ao nível de 5\% de probabilidade; ** Significativo ao nível de $1 \%$ e * de 5\% de probabilidade, pelo teste de F; NS=não significativo.

significativamente superior a apenas aos 21 dias (Tabela 1). Os benefícios do Si conferidos às plantas, são devidos a sua contribuição para a estruturação da parede celular de raízes e folhas. Portanto, este elemento não tem um papel metabólico definido nas plantas acumuladoras e sua ação, segundo Malavolta (1980) e Baldeon (1995), provoca efeitos indiretos, os quais, no conjunto contribuem para uma maior produtividade. Em tomateiro, Pereira et al. (2003) verificaram que a aplicação de escórias, xisto e termofosfato foram capazes de liberar silício para o solo e aumentar sua absorção pelas plantas, sendo no entanto, insuficiente para promover diferenças significativas no rendimento, todavia, comparativamente à testemunha sem aplicação, todos os tratamentos apresentaram-se ligeiramente superiores.

Na avaliação da massa fresca comercial, observou-se efeito significativo apenas para as doses, não se observando diferenças entre as épocas de aplicação que apresentaram variações entre 387,70 a 401,70 g/planta (Tabela 1). Assim como para a produção de massa fresca total ajustou-se um modelo quadrático através do qual se estima que com a dose 10,5 L/ha de Supa Potássio $^{\circledR}$ se obtém a maior massa fresca comercial (Figura 1). Ferreira et al. (2003) estudando doses de silifértil (resíduo industrial contendo $42 \%$ de $\mathrm{SiO}_{2}$ e outros macro e micronutrientes) não obser-

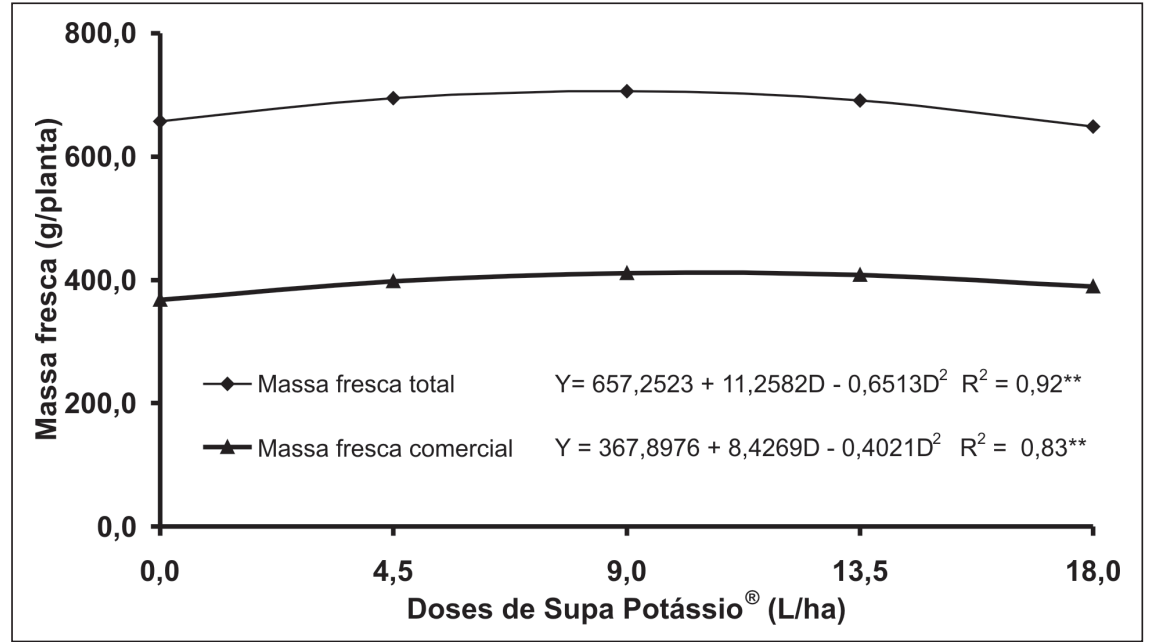

Figura 1. Massa fresca total e comercial de alface americana em função do uso de doses de Supa Potássio ${ }^{\otimes}$ (médias de quatro repetições). Três Pontas (MG), UFLA, 2002/2003.

varam efeitos significativos no rendimento da alface com o uso de até 4,0 t/ ha aplicados no solo. No entanto, comparando a testemunha sem aplicação com o uso da maior dose $(4,0$ t/ha), verificaram um incremento de $19,0 \%$ no peso comercial da alface cultivar Raider. O aumento da disponibilidade de Si para as plantas com conseqüente aumento de produtividade de algumas gramíneas (arroz, trigo, cana, sorgo, milho, milheto) e espécies não gramíneas (alfafa, feijão, soja, tomate, alface, repolho, pepino) é relatado por Korndörfer e Datnoff (1995). Marschener (1995) demonstrou incrementos significativos da taxa fotossintética devido às folhas ficarem mais eretas, melhorando a ar- quitetura foliar, afetando a interceptação de luz em populações densas de plantas, e de outros processos no metabolismo vegetal, tendo como resultado final um aumento e maior qualidade na produção.

Vale a pena salientar que o produto utilizado contém também $15,0 \%$ de $\mathrm{K}$, o que representou doses de 0,0 a 2,7 kg/ ha do nutriente aplicado juntamente com o silício via foliar em solução de $300 \mathrm{~L}$ de água/ha. Segundo Furlani (1997) há uma extração de $1,623 \mathrm{~kg} / \mathrm{ha}$ de potássio para cada 1000 plantas de alface, que transformadas para a densidade de plantio usada (95.238 plantas/ha) representa uma necessidade de $154,6 \mathrm{~kg} / \mathrm{ha}$ de potássio. Em termos percentuais a maior dose aplicada juntamente com o silício 


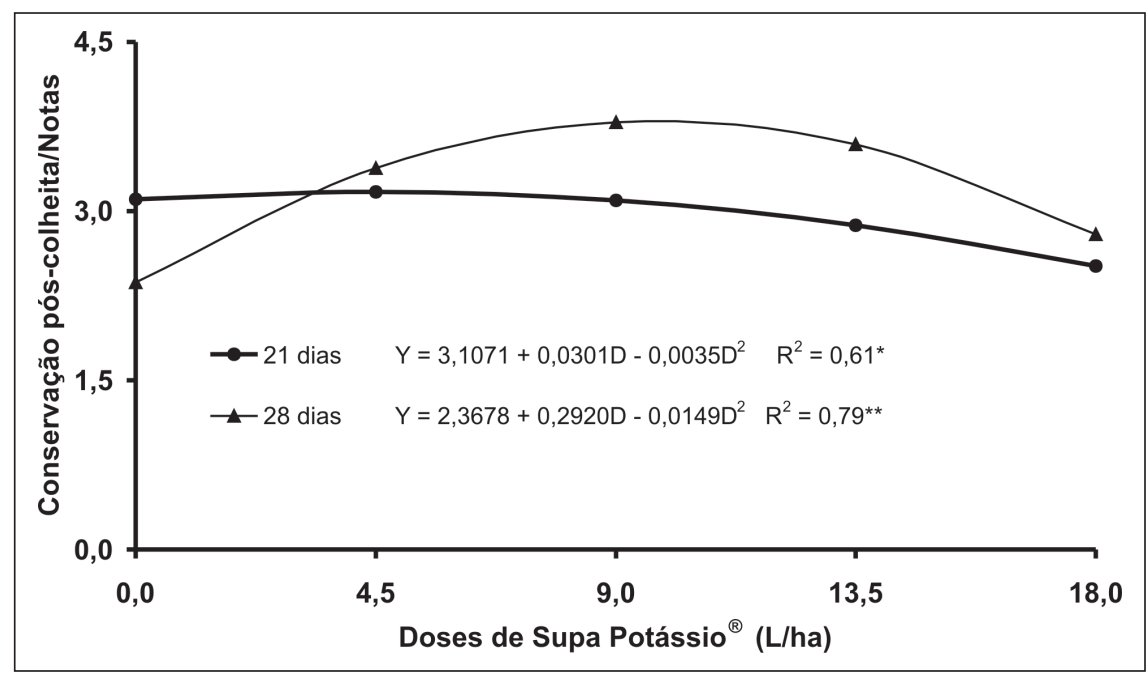

Figura 2. Conservação pós-colheita (20 dias) de alface americana em função do uso de doses de Supa Potássio ${ }^{\circledR}$ em duas épocas de aplicação (21 e 28 dias após o transplantio) (média de quatro repetições). Três Pontas (MG), UFLA, 2002/2003.

seria da ordem de $1,75 \%$ da necessidade da cultura de acordo com os referidos autores. Apesar da POTAFOS (1990) recomendar como técnicas de fertilização potássica o uso de adubações em sulcos, faixas, lanço e fertirrigação como as mais eficientes, evitando a aplicação foliar, que só é realizada de forma emergêncial, a pequena quantidade utilizada não pode ser totalmente desprezada, mesmo sendo utilizada a adubação potássica no plantio e em cobertura de acordo com a análise do solo. No entanto, respostas a adubação potássica em alface americana só foram obtidas por Mota (1999), para as características de produção na dose de 113,77 kg/ha e por Madeira et al. (2000) com 99,0 kg/ha, aplicadas ao solo.

A circunferência da cabeça comercial não apresentou efeitos significativos, com variações de 37,01 a $37,73 \mathrm{~cm}$ dentro das épocas de aplicação e 37,08 a 37,65 cm dentro de doses (Tabela 1); assim como também o comprimento de caule da cabeça comercial. Vale salientar, com relação ao comprimento do caule, que verificou-se uma variação entre as doses de Supa Potássio ${ }^{\circledR}$ de 6,15 a $6,45 \mathrm{~cm}$ e entre épocas de aplicação de 6,02 a 6,40 cm (Tabela 1). Menores comprimentos de caule são desejáveis para a alface americana, principalmente quando destinada à indústria de beneficiamento, devendo ser bastante reduzido, proporcionando menores perdas durante o processamento. Por outro lado o caule excessivamente comprido acarreta uma menor compacidade da cabeça e dificulta o beneficiamento, afetando a qualidade final do produto (YURI et al., 2002; RESENDE et al., 2003). Na prática, caules com até 6,0 $\mathrm{cm}$ seriam os mais adequados, sendo aceitáveis até o patamar de 9,0 cm e inaceitáveis ou menos recomendados para processamento aqueles acima deste valor (RESENDE, 2004). Neste contexto, tanto as doses com as épocas de aplicação proporcionaram comprimento de caule próximos ao considerado como adequado e aceitável, não afetando a qualidade do produto final.

Com relação à conservação pós-colheita não se observou diferenças significativas dos tratamentos para a avaliação aos 10 dias, com variações de notas de 4,47 a 4,60 dentro das épocas de aplicação e 4,56 a 4,67 dentro de doses (Tabela 1). Estes resultados concordam com os obtidos por Resende (2004) e Yuri (2004) que estudando outros nutrientes, também não observaram efeitos significativos na conservação 10 dias após a colheita, assim como corroboram os relatos de Decateau et al. (1995), que afirmam ter a alface americana maior conservação pós-colheita comparativamente a outros tipos da mesma espécie. Para a conservação 20 dias após a colheita foi verificada uma interação entre os fatores estudados (Figura 2). Para aplicação aos 21 dias após o transplante evidenciou-se um efeito quadrático onde a dose de 4,3 L/ha de Supa Potássio ${ }^{\circledR}$ promoveu a melhor conservação póscolheita da alface. Resultados similares foram observados para a aplicação aos 28 dias após o transplante onde ajustouse um modelo quadrático, no qual a dose de 9,8 L/ha proporcionou a maior conservação. Quando se analisa apenas a época de aplicação (Tabela 1) observase que apesar da aplicação aos 28 dias após o transplante alcançar melhores notas esta não foi significativamente superior à aplicação aos 21 dias. A ação benéfica do silício tem sido associada a diversos efeitos indiretos como o aumento na eficiência da capacidade fotossintética, redução da transpiração, aumento da resistência mecânica das células, da resistência a insetos e doenças, redução da acumulação tóxica de $\mathrm{Mn}, \mathrm{Fe}$ e Al e outros metais pesados, e aumento na absorção do P (KORNDÖRFER; DATNOFF, 1995), o que provavelmente auxiliaria em uma maior conservação e possivelmente viabilizaram esta resposta positiva da aplicação de Supa Potássio $^{\circledR}$, na maior conservação pós-colheita da alface americana. Em termos de adubação potássica aos 21 e 28 dias foram aplicados 0,64 e 1,47 kg/ha, respectivamente, juntamente as doses de silício. Yuri (2004) avaliando a conservação pós-colheita da alface americana em cultivo de verão observou efeitos significativos da adubação potássica aplicada no plantio e em cobertura aos $14 \mathrm{e}$ 21 dias, nas doses de 180,8 e 182,2 kg/ ha, respectivamente.

Concluiu-se que as doses de 8,6 e 10,5 L/ha de Supa Potássio ${ }^{\circledR}$ resultaram em maiores rendimentos, respectivamente, de massa fresca total e comercial, sendo recomendada sua aplicação aos 14 dias após o transplante. Com relação à conservação pós-colheita as doses de 4,3 e 9,8 L/ha propiciaram a melhor conservação quando aplicadas aos 21 e 28 dias após o transplante. Neste contexto, a aplicação de Supa Potássio ${ }^{\circledR}$ mostrou-se de relevante importância, tanto para o incremento da produtividade, como para uma melhor conservação pós-colheita da alface americana em cultivo de verão, inferindo-se ser o silício aplicado, o principal nutriente em termos de resposta, em função da alta exigência de potássio pela cultura, assim como das respostas à adubação potássica mostra- 
rem-se significativas de acordo com a literatura, somente em doses bem mais elevadas. No entanto, os resultados obtidos sugerem ainda novos trabalhos utilizando maiores doses e períodos de aplicação, tanto no verão como no inverno, de forma a consolidar ou não, a atuação do silício como importante nutriente na produção e qualidade pós-colheita da alface americana.

\section{LITERATURA CITADA}

ADATIA, M.H.; BESFORD, R.T. The effects of silicon on cucumber plants grown in recirculating nutrient solution. Annals of Botany, London, v.58, n.3, p.343-351, 1986.

ALVAREZ V., V.H.; RIBEIRO, A.C. Calagem. In: RIBEIRO, A.C.; GUIMARÃES, P.T.G.; ALVAREZ V., V.H. (eds.). Recomendações para o uso de corretivos e fertilizantes em Minas Gerais. Viçosa: CFSEMG, 1999. 359 p. (5'Aproximação).

BALDEON, J.R.M. Efeito da ação alcalinizante e da competição entre silicato e fosfato na eficiência do termofosfato magnesiano em solos ácidos. 1995. 85 f. (Tese doutorado) - ESALQ, USP, Piracicaba.

BARBOSA FILHO, M.P.; SNYDER, G.H.; FAGERIA, N.K.; DATNOFF, L.E.; SILVA, O.F. Silicato de cálcio como fonte de silício para o arroz de sequeiro. Revista Brasileira de Ciências do Solo, Piracicaba, v.25, n.2, p.325-330, 2001.

CARVALHO, R.; FURTINI NETO, A.E.; CURJ, N.; FERNANDES,L.A.; OLIVEIRA, JR. A.C. Dessorção de fósforo por silício em solos cultivados com eucalipto. Revista Brasileira de Ciências do Solo, Viçosa, v.24, n.1, p.69-74, 2000.

DECATEAU, D.R.; RANWALA, D.; McMAHON M.J.; WILSON, S.B. The lettuce growing handbook: botany, field procedures, growing problems, and postharvest handling. Illinois: Oak Brook, 1995. 60 p.

DOUGLAS, J.S. Advanced guide to hidroponics: Soilless cultivation. 5.ed. London: Pelham Books, $1985.368 \mathrm{p}$.
EPSTEIN, E. The anomaly of silicon in plant biology. Proceedings of National Academy of Sciences of the United States of América, Washington, v.91, n.1, p.11-17, 1994.

FAQUIN, V. Nutrição mineral de plantas. Lavras: FAEPE. 1997, $227 \mathrm{p}$.

FERREIRA, R.L.F.; SOUZA, J.R.; CARVALHO, J.G.; ARAÚJO NETO, S.E..; YURI, J.E. Produção e rendimento de cultivares de de alface adubadas com Silifértil. In: Congresso Brasileiro de Olericultura - Anais CBO 2003. Disponível em <http://www.horticiencia.com.br/> Acesso em: 27 mai 2004.

FURLANI, P.R. Introduções para o cultivo de hortaliças de folhas pela técnica de hidroponia NFT. Campinas: Instituto Agronômico, 1997. 30 p. (Boletim Técnico, 168).

HOPKINS, W.G. Introduction to plant physiology. New York: John Wiley, 1995. 464 p.

HORST, W.J.; MARSCHNER, H. Effect of silicon on manganese tolerance of bean plants (Phaseolus vulgaris L.). Plant and Soil, Dordrecht, v.50, n.2, p.287-303, 1978.

KORNDÖRFER, G.H.; DATNOFF, L.E. Adubação com silício: uma alternativa no controle de doenças da cana de açúcar e do arroz. Informações Agronômicas, Piracicaba, n.70, p.1-3, 1995. LEITE, P.C. Interação silício-fósforo em latossolo roxo cultivado com sorgo em casa de vegetação. 1997. 87 f. (Tese doutorado) - UFV, Viçosa.

MADEIRA, N.R.; YURI, J.E.; FREITAS, S.A.C.; RODRIGUES JÚNIOR, J.C. Fornecimento de nitrogênio, potássio e cálcio para a alface americana via fertirrigação. In: CONGRESSO BRASILEIRO DE OLERICULTURA, 40., 2000. São Pedro. Anais... São Pedro: SOB/FCAV-UNESP, 2000. p.841-842.

MALAVOLTA, E. Elementos de nutrição mineral de plantas. São Paulo: editora Agronômica Ceres, 1980. $251 \mathrm{p}$.

MARSCHNER, H. Mineral nutrition of higher plants. 2.ed. London: Academic Press, 1995. 889 p. MENGEL, K.; KIRKBY, E.A. Principles of plant nutrition. 4. ed. Bern: International Potash Institute, 1987. $687 \mathrm{p}$.

MOTA, J.H. Efeito do cloreto de potássio via fertirrigação na produção de alface americana em cultivo protegido. 1999. 46 f. (Tese mestrado) UFLA, Lavras.
PEREIRA, H.S.; VITTI, G.C.; KORNDÖRFER, G.H. Comportamento de diferentes fontes de silício no solo e na cultura do tomateiro. Revista Brasileira de Ciências do Solo, Viçosa, v.27, n.1, p.101-108, 2003.

POTAFOS - Associação Brasileira para a Pesquisa da Potassa e do Fosfato. Potássio: necessidade e uso na agricultura moderna. Piracicaba: POTAFOS, 1990. 45 p.

RAIJ, B. Fertilidade do solo e adubação. Piracicaba: Agronômica Ceres \& Potafos, 1991. $343 \mathrm{p}$.

RESENDE, G.M. Características produtivas, qualidade pós-colheita e teor de nutrientes em alface americana (Lactuca sativa $L$.) sob doses de nitrogênio e molibdênio, em cultivo de verão e de inverno. 2004. 139 f. (Tese doutorado) - UFLA, Lavras.

RESENDE, G.M.; YURI, J.E.; MOTA, J.H.; SOUZA, R.J.; FREITAS, S.A.C.; RODRIGUES JÚNIOR, J.C. Efeitos de tipos de bandejas e idade de transplantio de mudas sobre o desenvolvimento e produtividade de alface americana. Horticultura Brasileira, Brasília, v.21, n.3, p.562567, 2003

RISSE, L.A.; McDONALD, R.E.; BARMORE, C.E. Packaging chopped lettuce in film bags. St. Joseph: ASAE, 1989. 10p. (Paper no 89-6037).

TAKAHASHI, E.; MIYAKE, Y. Silica and plant growth. In: Proceedings International Seminar on Soil Environment and Fertilty Managment in Intensive Agriculture. Tokio: Nippon Dojohiryo Gakkai, 1997. p.603-611.

TISDALE, S.L.; NELSON, W.L.; BEATON, D.J. Soil fertility and fertilizers. 4 ed. New York: Macmillan Publishing Company, 1985. 754 p.

YURI, J.E. Produção, nutrição e conservação póscolheita da alface tipo americana, cv. Raider, no verão e no inverno, em função da aplicação de nitrogênio e potássio em cobertura. 2004. $139 \mathrm{f}$. (Tese doutorado) - UFLA, Lavras.

YURI, J.E.; SOUZA, R.J.; FREITAS, S.A.C.; RODRIGUES JÚNIOR, J.C.; MOTA, J.H. Comportamento de cultivares de alface tipo americana em Boa Esperança. Horticultura Brasileira, Brasília, v.20, n.2, p.229-232, 2002. 